\title{
Recent Developments and Current Issues in the Epidemiology, Diagnosis, and Management of Bacterial and Fungal Neonatal Sepsis
}

\author{
Andi L. Shane, MD, MPH, MSc ${ }^{1}$ Barbara J. Stoll, MD² \\ ${ }^{1}$ Division of Infectious Disease, Department of Pediatrics, Emory \\ University School of Medicine, Atlanta, Georgia \\ 2 Department of Pediatrics and Children's Healthcare of Atlanta, \\ Emory University School of Medicine, Atlanta, Georgia
}

\begin{abstract}
Address for correspondence and reprint requests Andi L. Shane, MD, MPH, MSc, Division of Infectious Disease, Emory University School of Medicine, 2015 Uppergate Drive NE, Atlanta, GA. 30322
\end{abstract}

(e-mail: ashane@emory.edu).

\begin{abstract}
Keywords

- neonatal sepsis

- invasive candidiasis

- epidemiology

- management

Identifying neonates with sepsis is complicated by variability in clinical presentation. The incidence of early onset sepsis (EOS) resulting from invasive group B streptococcal (GBS) infections has been notably reduced by the widespread delivery of intrapartum antibiotic prophylaxis. Rates of EOS attributable to non-GBS etiologies have remained constant, and ampicillin-resistant Escherichia coli has become more prevalent. Lateonset sepsis (LOS) attributable to gram-positive organisms including coagulase-negative Staphylococci and Staphylococcus aureus is associated with increased morbidity and mortality among premature infants. Invasive candidiasis is an emerging cause of LOS, especially among infants who receive broad-spectrum antimicrobial agents. Prophylactic fluconazole administration to very low-birth-weight (VLBW) neonates during the first 6 weeks of life prevents invasive candidiasis in neonatal intensive care units (NICU) with high rates of fungal infections. Targeted fluconazole prophylaxis may be beneficial in VLBW neonates who receive care in NICUs with lower rates of invasive fungal infections. Assessment of immune function, neutrophil markers, acute phase reactants, and utilization of sepsis screening scores may contribute to the management of sepsis. Maternal decolonization, antimicrobial stewardship, early enteral feeding, and optimal infection control practices are potential practical strategies for reducing the burden of neonatal sepsis.
\end{abstract}

The definition of neonatal sepsis is complicated by the frequent presence of noninfectious conditions that resemble those of sepsis, especially in very low-birth-weight (VLBW) preterm infants and by the absence of optimal diagnostic tests. Although growth of an organism from a sterile site is the "gold standard" for definitive diagnosis, it is not always possible to isolate a causative pathogen. Invasive infections can occur in seemingly asymptomatic neonates. Therefore, assessment of history and risk factors in combination with diagnostic tests are used to identify neonates who are more likely to be infected.

received

August 23, 2012

accepted after revision

December 7, 2012

published online

July 6, 2012

The definitions of early onset sepsis (EOS) and late onset sepsis (LOS) are subject to subspecialist variation. Many investigators, including those who participate in the Eunice Kennedy Shriver National Institute of Child Health and Human Development (NICHD) Neonatal Network and the Vermont Oxford Network, define EOS by the onset of signs/symptoms and an associated positive culture at or before 72 hours of life. LOS is characterized by the onset of symptoms consistent with sepsis at greater than 72 hours of life. These classifications of EOS and LOS reflect the differing etiologies and proposed pathophysiology of pathogens commonly associated with the timing of

Copyright $\odot 2013$ by Thieme Medical Publishers, Inc., 333 Seventh Avenue, New York, NY 10001, USA. Tel: +1(212) 584-4662.
DOI http://dx.doi.org/ 10.1055/s-0032-1333413. ISSN 0735-1631. 
onset of these conditions. The impaired innate immune function of premature infants predisposes them to invasive infections. As the fetal immune response begins at 24 weeks of age and development occurs until term, premature neonates do not benefit from complete immune system development, making them more susceptible to infection with organisms that term infants may be able to suppress. ${ }^{1}$

\section{Early Onset Sepsis}

Risk factors for EOS include prematurity and associated immunologic immaturity, ${ }^{2}$ maternal group B streptococcal (GBS) colonization, rupture of membranes greater than 18 hours, and maternal intra-amniotic infection. ${ }^{3,4}$ The maternal vaginal flora is the most common source of organisms associated with EOS. Maternal pathogens are introduced during passage through the birth canal or with ascending maternal infection in a fetus that inhales or digests infected amniotic fluid. Chorioamnionitis is defined as a maternal fever $>38^{\circ} \mathrm{C}$ and two or more of the following: maternal leukocytosis $>15,000$ cells $/ \mathrm{mm}^{3}$, maternal tachycardia $>100$ beats per minute, fetal tachycardia $>160$ beats per minute, uterine tenderness, or a foul odor to the amniotic fluid. ${ }^{5}$ Although maternal fever occurs in one in four or five laboring women who receive epidural anesthesia, histological or microbiologic chorioamnionitis rarely occurs in women with an isolated fever. ${ }^{6}$ Surveillance of high-risk preterm infants at 20 academically affiliated neonatal intensive care units (NICUs) of the NICHD Neonatal Research Network (NRN) noted that between $14 \%$ and $28 \%$ of women with preterm deliveries at 22 to 28 weeks' gestation had clinical presentations consistent with chorioamnionitis. ${ }^{7}$ In contrast, in an earlier study under $1 \%$ of women with term gestations had recovery of organisms by culture from their amniotic fluid. ${ }^{8}$ Among women who experienced preterm labor with intact membranes, $32 \%$ had one or more organisms isolated from their amniotic fluid, and the amniotic fluid of almost threequarters of women with preterm premature rupture of membranes (PPROM) yielded one or more organisms. ${ }^{9}$ In another study of women with preterm deliveries at 23 to 32 weeks' gestation, $23 \%$ infants were found to have cord blood cultures positive for Ureaplasma spp. or Mycoplasma spp., suggesting that these intrauterine infections may be more frequent than previously appreciated. ${ }^{10}$

\section{Bacterial Pathogens}

GBS and Escherichia coli are the most common pathogens associated with EOS in the United States. ${ }^{11,12}$ Populationbased surveillance from 2005 to 2008 conducted through the Active Bacterial Core sites identified 658 cases of EOS from 2005 to 2008; 72 (11\%) were fatal. Overall incidence remained stable during the 3 years at 0.76 to 0.77 cases/1,000 live births. GBS (38\%) was the most commonly reported pathogen followed by $E$. coli (24\%). African-American preterm infants had the highest incidence (5.14 cases/1,000 live births) and case fatality (24.4\%). The estimated national annual burden of EOS was $~ 3,320$ cases (95\% confidence interval [CI]: 3,060 to 3,580), including 390 deaths ( $95 \% \mathrm{CI}$ : 300 to 490). The burden of EOS among preterm infants was slightly less than half of the total number of EOS cases. ${ }^{11}$ A study from the NICHD NRN of almost 400,000 infants born at NRN hospitals reported an overall rate of EOS of 0.98 cases per 1,000 live births, with rates for GBS and $E$. coli of $0.41 / 1,000$ live births and $0.28 / 1,000$ live births, respectively. Most infants with GBS were term $(73 \%)$; most with $E$. coli were preterm $(81 \%) .^{12}$ Between 1997 and 2010, 1,032 cases of EOS were identified among 108,000 VLBW admissions to 313 community based NICUs. Gram-negative organisms were isolated most frequently in this VLBW cohort with an increased risk of death among infants with EOS (odds ratio [OR] 1.45; $95 \% \mathrm{CI}$ : 1.21 to 1.73 ). ${ }^{13}$

\section{Group B Streptococci}

Prior to universal recommendations for intrapartum antibiotic prophylaxis (IAP) in at-risk women, almost half of infants born to women colonized with GBS developed invasive early onset GBS disease. ${ }^{14,15}$ Recommendations for IAP in women who are colonized with GBS or have other risk factors for EO GBS have been instrumental in reducing the rates of EO GBS disease. ${ }^{16}$ Despite the benefit of IAP, rates of uptake are limited by inadequate screening practices and missed opportunities to administer IAP. ${ }^{12}$ Additionally, the efficacy of IAP has only been demonstrated for EOS attributable to GBS; IAP does not prevent LOS. With increasing use of IAP, concerns have been raised about an increase in non-GBS EOS and about increasing risk of antimicrobial resistance. Most population-based studies report stable rates of EOS caused by non-GBS pathogens. ${ }^{17}$ However, several studies have suggested that ampicillin-resistant $E$. coli may be increasing, especially among VLBW infants. ${ }^{18,19}$

\section{Late-Onset Sepsis}

LOS is a frequent complication of extreme prematurity. Several studies from the NICHD NRN have documented rates of infection among VLBW ( $<1,500 \mathrm{~g})$ infants. In a recent study, $36 \%$ of 9,575 extremely low-gestational-age infants (22 to 28 weeks) developed LOS. ${ }^{7}$ An earlier NRN study reported that $21 \%$ of 6,215 VLBW infants who survived more than 3 days developed LOS. Gram-positive organisms are most commonly associated with LOS among VLBW infants. In the NRN cohort, $70 \%$ of infections were associated with grampositive organisms; coagulase-negative staphylococci (CoNS) contributed $48 \%$, gram-negative $18 \%$, and fungal $12 \%$. In some evaluations, more than one organism was isolated. ${ }^{18}$ The predominance of gram-positive organisms among VLBW infants was also seen in a large study of community-based NICUs over a 14-year period. Among 12,204 cases of LOS, gram-positive organisms were most frequent. ${ }^{13}$ Several studies have noted an increased risk of mortality among infants with LOS compared with those who are uninfected. ${ }^{13,18,20}$ Understanding the epidemiology of LOS helps to identify infants with possible infection and also to select appropriate empiric antimicrobial therapy while awaiting culture results.

\section{Coagulase-Negative Staphylococci}

In a large retrospective cohort study conducted in 248 NICUs from 1997 to 2009, 17,624 episodes of CoNS sepsis were 
identified among 16,629 VLBW infants; most episodes were classified as possible infections. Infants with lower birth weights and gestational age were more likely to have a CoNS isolated during an episode of sepsis. A CoNS infection was characterized as isolation of the organism from two or more blood cultures, one blood culture and one other sterile site, or one blood culture with a significant infection. The number of central lines, clinical presentation of lethargy, and gastric acid residuals but not central line duration were risk factors for a CoNS infection. ${ }^{21}$ As CoNS are frequently isolated from neonates with clinical sepsis, it is important to understand risk factors for their recovery and strategies to decrease their prevalence to optimize management.

\section{Staphylococcus aureus}

A retrospective evaluation of NICHD NRN sites from 2007 to 2009 identified 8,444 VLBW neonates who survived greater than 3 days. Among these infants, 316 (3.7\%) had Staphylococcus aureus bacteremia or meningitis; 88 infants had methicillin-resistant Staphylococcus aureus (MRSA) infections, 228 infants had methicillin-susceptible Staphylococcus aureus (MSSA) infections, and there were no coinfections. Almost all of the infants who had MRSA infections had manifestations after 7 days of age. Nine of 20 participating centers had no cases of MRSA. Morbidities did not differ between neonates with MRSA and MSSA infections. Although S. aureus infections comprised only $1 \%$ of all-cause bacteremia and meningitis, mortality rates of neonates with both MRSA and MSSA infections were high (26\% and $24 \%$, respectively) and comparable. ${ }^{22}$

\section{Candidiasis}

Although less frequent than gram-positive or gram-negative infections, invasive infections with fungal organisms, primarily Candida spp., result in substantial morbidity and mortality. ${ }^{23,24}$ Approximately $2.5 \%$ of all bloodstream infections in VLBW neonates are estimated to be due to fungal etiologies. ${ }^{25}$ The risk for fungal sepsis is increased by colonization acquired vertically from maternal sources as well as horizontally from the NICU environment. A positive correlation exists between multiple sites of colonization and risk for invasive candidiasis. $^{23}$ Risk factors supporting the use of empiric antifungal therapy in a neonate exhibiting signs and symptoms of sepsis include gestational age, exposure to third-generation cephalosporin antibiotics in the 7 days prior to symptom onset, and thrombocytopenia. ${ }^{26}$ Invasive candidiasis occurred in 137 of $1,515(9 \%)$ of neonates weighing $<1,000 \mathrm{~g}$ at birth in a prospective observational cohort study conducted in 19 NICHD NRN sites. Incidence of invasive infection varied from $2 \%$ to $28 \%$ among the sites that enrolled more than 50 neonates. ${ }^{27}$ Overall mortality in a cohort of 730 infants with invasive candidiasis from 192 NICUs enrolled between 1997 and 2003 was $19 \%{ }^{28}$ Among infants weighing between 401 and 1,000 g at birth born between 1993 and 2001 who had an invasive fungal infection, 31 (30\%) had a head circumference less than the 10th percentile at 18 to 22 months of corrected gestational age, a statistically significant $(p<0.05)$ difference compared with uninfected neonates and comparable to neonates with gram-negative invasive infections. ${ }^{29}$

\section{Special Populations}

As surgical techniques to correct congenital cardiac anomalies have become more successful, the survival of infants with these conditions has improved. Extended hospitalizations for surgical recovery and rehabilitation place these neonates at risk for sepsis. Among a cohort of 11,638 infants with congenital heart disease (CHD) receiving care in 250 U.S. NICUs from 1996 to 2007, 656 (6\%) neonates had 821 episodes of sepsis, resulting in a cumulative incidence of 71/1,000 admissions. Gram-positive organisms, most commonly CoNS and S. aureus, were isolated in (64\%) of episodes. Similar to infants without CHD, infants with CHD and culture-proven sepsis were more likely to die than uninfected infants with CHD. Mortality rates were highest for infants with candidemia followed by those with gram-negative bacteremia. ${ }^{30}$ Most studies of neonates with CHD include both term and preterm neonates, accounting for the lower overall rates of sepsis and the comparatively lower rates of gram-negative bacteremia and candidemia than are noted when analysis is limited to preterm infants.

\section{Diagnostics}

One of the most challenging aspects in the management of neonates with sepsis is making the diagnosis. Many of the complications of prematurity, including respiratory distress syndrome and CHD, have similar manifestations to those associated with sepsis. Several physiological and laboratory parameters have been assessed to diagnose sepsis in neonates (-Table 1).

\section{Culture-Based Diagnostics}

\section{Blood Culture}

Blood culture is the gold standard diagnostic test for neonatal sepsis. At least $1 \mathrm{~mL}$ of whole blood inoculated into each blood culture bottle provides an optimal specimen. Up to $25 \%$ of neonates with bacterial sepsis have a low organism burden that would not be detected with culture of smaller blood volumes. ${ }^{31,32}$ Blood cultures of adequate volume are twice as likely to yield an organism than blood cultures containing a lesser blood volume. ${ }^{33}$

\section{Cerebrospinal Fluid Culture}

Evaluation of the cerebrospinal fluid (CSF) is needed to diagnose meningitis. A lumbar puncture is recommended for all infants with suspected sepsis or with blood cultureproven bacteremia, if they have stable cardiorespiratory and coagulation status. Meningitis occurs in up to $23 \%$ of bacteremic infants. ${ }^{34,35}$ Organisms are not isolated from blood in up to $38 \%$ infants who have a pathogen isolated from the CSF, underscoring the importance of examining the $\mathrm{CSF}^{36,37}$

\section{Urine Culture}

Most clinicians do not obtain a urine culture as part of an EOS evaluation as it is unusual for a neonate to develop a urinary tract infection in the first 72 hours, without associated bacteremia. A urine culture may be useful as part of an evaluation for 
134 Neonatal Sepsis Update Shane, Stoll

Table 1 Culture-based and non-culture-based diagnostics for neonatal sepsis

\begin{tabular}{|c|c|c|c|}
\hline Category & Parameter & $\begin{array}{l}\text { Optimal timing, } \\
\text { volume of specimen, } \\
\text { routine/investigationala }^{\text {a }}\end{array}$ & $\begin{array}{l}\text { Applicability for neonatal } \\
\text { sepsis }\end{array}$ \\
\hline \multicolumn{4}{|l|}{ Culture-based } \\
\hline Blood & Culture & $\begin{array}{l}>1 \mathrm{~mL} \text { of whole blood } \\
\text { Routine }\end{array}$ & Gold standard for bacteremia \\
\hline CSF & Culture & $\begin{array}{l}\text { When clinically feasible } \\
\text { Routine }\end{array}$ & Optimize antimicrobial therapy \\
\hline Urine & Culture & $\begin{array}{l}>72 \text { h of life } \\
\text { Routine }\end{array}$ & $\begin{array}{l}\text { Not useful for EOS; potential } \\
\text { benefits for LOS }\end{array}$ \\
\hline Tracheal aspirate & Culture & Routine & Usually reflects colonization \\
\hline \multicolumn{4}{|l|}{ Non-culture-based } \\
\hline Immune function & $\begin{array}{l}\text { MHC II } \\
\text { TNF- } \alpha\end{array}$ & $\begin{array}{l}\text { Investigational } \\
\text { Investigational }\end{array}$ & $\begin{array}{l}\text { Both decreased in chorioamnionitis } \\
\text { and sepsis }\end{array}$ \\
\hline Neutrophil indices & $\begin{array}{l}\text { Neutropenia } \\
\text { Absolute neutrophil count } \\
\text { Absolute immature } \\
\text { neutrophil count }\end{array}$ & $\begin{array}{l}\text { After } 12 \text { h of life } \\
\text { Consider GA, delivery mode, } \\
\text { altitude, arterial versus venous } \\
\text { sampling, time since birth } \\
\text { Routine }\end{array}$ & $\begin{array}{l}\text { Neutropenia better predictor for } \\
\text { sepsis than leukocytosis }\end{array}$ \\
\hline Neutrophil markers & CD64 & $\begin{array}{l}\text { Elevated for } 24 \text { h after infection } \\
\text { Requires } 50 \mu \mathrm{L} \text { blood } \\
\text { Results within hours } \\
\text { Investigational }\end{array}$ & $\begin{array}{l}\text { Cut points between } 2.38 \text { and } \\
3.62 \text { optimal sensitivity, specificity } \\
\text { and NPV for EOS }\end{array}$ \\
\hline Platelet count & $\begin{array}{l}\text { Thrombocytopenia } \\
\text { and thrombocytosis }\end{array}$ & $\begin{array}{l}\text { Late findings; slow to respond } \\
\text { Routine }\end{array}$ & $\begin{array}{l}\text { Thrombocytopenia associated } \\
\text { with fungal infection }\end{array}$ \\
\hline CSF cell count & $\begin{array}{l}\text { CSF } \\
\text { WBC }\end{array}$ & $\begin{array}{l}\text { Uninfected neonates: mean } \\
10 \text { cells } / \mathrm{mm}^{3} ; \text { range up to } \\
20 \text { cells } / \mathrm{mm}^{3} \\
\text { Routine }\end{array}$ & $\begin{array}{l}\text { Does not predict culture-proven } \\
\text { meningitis }\end{array}$ \\
\hline CSF chemistries & $\begin{array}{l}\text { CSF protein } \\
\text { CSF glucose }\end{array}$ & $\begin{array}{l}\text { Term }<100 \mathrm{mg} / \mathrm{dL} \\
\text { Preterm higher; } 70-80 \% \\
\text { of serum glucose } \\
\text { Routine }\end{array}$ & $\begin{array}{l}\text { Elevated in fungal meningitis } \\
\text { Low glucose specific for } \\
\text { bacterial meningitis }\end{array}$ \\
\hline Acute phase reactants & $\begin{array}{l}\text { CRP } \\
\text { Procalcitonin }\end{array}$ & $\begin{array}{l}8-24 \mathrm{~h} \text { after infection } \\
2-12 \mathrm{~h} \text { after infection } \\
\text { Routine/investigational }\end{array}$ & $\begin{array}{l}\text { Good NPV } \\
\text { Better sensitivity but less } \\
\text { specificity than CRP }\end{array}$ \\
\hline Sepsis panels/ scores & & $\begin{array}{l}\text { After } 24 \text { h of life } \\
\text { Investigational }\end{array}$ & $\begin{array}{l}\text { Most useful for NPV and } \\
\text { discontinuation of } \\
\text { antimicrobial therapy }\end{array}$ \\
\hline
\end{tabular}

Abbreviations: CRP, C-reactive protein; CSF, cerebrospinal fluid; EOS, early onset sepsis; GA, gestational age; LOS, late onset sepsis; MHC II, major histocompatibility complex class II; NPV, negative predictive value; TNF, tumor necrosis factor; WBC, white blood cell count.

${ }^{a}$ Routine refers to an assay or parameter that is routinely available and widely used; investigational refers to an assay or parameter that is undergoing evaluation for clinical use and applicability.

LOS, especially when colonization with Candida is suspected. A secondary analysis of the NRN Early Diagnosis of Nosocomial Candidiasis study demonstrated that extremely low-birthweight (ELBW) infants with candiduria, both with and without isolation of the organism from additional sterile sites, had a greater risk of neurodevelopmental impairment or death than those ELBW infants with suspected but unproven infection. The authors conclude that the isolation of Candida spp. from the urine of an ELBW neonate should result in an investigation for evidence of invasive infection with prompt initiation of treatment. ${ }^{38}$ Both bacterial organisms and yeast will grow in urine cultures undergoing routine bacterial culture; thus a request for a fungal urine culture is not needed for diagnosis of candiduria.

\section{Tracheal Aspirate Cultures}

Collection of tracheal aspirates after placement of an endotracheal tube is unlikely to be of diagnostic value and will likely reflect colonization rather than infection.

\section{Non-Culture-Based Diagnostics}

In addition to blood, CSF, and urine cultures, non-culturebased laboratory tests may be beneficial in identifying infected neonates and in deciding on duration of antimicrobial 
therapy (-Table 1). Non-culture-based tests may be more helpful in identifying neonates who are unlikely to have infection, when culture-based methods are inconclusive. ${ }^{39}$

\section{Immune Function}

Immune response in the premature neonate and the relationship to infection is an active area of investigation. Reduced expression of major histocompatibility complex class II in neonates has been associated with a history of maternal preterm labor and PPROM, chorioamnionitis, and neonatal sepsis. Whole blood lipopolysaccharide stimulation assays were notable for decreased tumor necrosis factor- $\alpha$ production in preterm infants who subsequently developed sepsis. Other mechanisms of impaired immune response include in utero exposure to inflammation prior to preterm delivery leading to "endotoxin hyporesponsiveness," thus increasing the risk for sepsis and end-organ sequelae. ${ }^{40}$

\section{Neutrophil Number and Function}

Term and late preterm neonates have impaired neutrophil function compared with that of older infants. Early onset neutropenia might predispose neonates to colonization with pathogens and subsequent EOS or LOS. Neutropenia appears to be a better predictor for neonatal sepsis than leukocytosis, although neutropenic ranges differ by gestational age, mode of delivery, altitude of location of birth, arterial versus venous sampling, and time since birth. A white blood cell count (WBC) obtained within the first 6 to 12 hours of life may be too early to reflect an occult inflammatory response and could be repeated if sepsis is suspected. ${ }^{41,42}$ Two very large retrospective multicenter administrative database studies demonstrated that low WBC and high percentage of immature to total white blood cell ( $\mathrm{I} / \mathrm{T}$ ratios) were associated with increasing odds of infection in EOS. ${ }^{43}$ High and low WBC, high Absolute Neutrophil count (ANC), high $\mathrm{I} / \mathrm{T}$ ratios, and low platelet counts were associated with LOS. ${ }^{44}$ However, a single blood cell count-derived index did not have proven sensitivity to reliably exclude EOS or LOS in neonates. ${ }^{43,44}$ The absolute immature neutrophil count and absolute neutrophil count have suboptimal sensitivity and decreased predictive accuracy for EOS as elevation does not consistently distinguish an inflammatory response from a noninfectious etiology. ${ }^{45}$ The $\mathrm{I} / \mathrm{T}$ ratio is a more sensitive indicator of sepsis; however, single assessments have a better negative predictive value (99\%) than positive predictive value $(25 \%) .{ }^{46}$ The $\mathrm{I} / \mathrm{T}$ ratio is elevated in a quarter to half of presumptively uninfected neonates. ${ }^{47}$ Overall, neutrophil indices seem to be more helpful for excluding infants without infection than for including infants with infection. ${ }^{39}$

\section{Neutrophil Markers}

The CD64 neutrophil marker has been noted to be elevated for 24 hours following infection in neonates with culture-confirmed sepsis. A prospective single-center study demonstrated that a CD64 index with a cut point of 2.38 had $100 \%$ sensitivity and specificity and 68\% negative predictive value for EOS. A cut point of 3.62 had a sensitivity of $75 \%$, specificity of $77 \%$ and a negative predictive value of $96 \% .{ }^{48}$ Index values below the cut points could be used to support the discontin- uation of antimicrobials. Advantages of this assay include the requirement for only $50 \mu \mathrm{L}$ of blood and availability of results within hours of the specimen being obtained. ${ }^{49}$ However, determination of the surface expression of CD64 on neutrophils requires the use of flow cytometry that has limited its utility, except at specialized centers with 24-hour flow cytometry access and support.

\section{Platelet Count}

Thrombocytopenia and thrombocytosis are later findings in bacterial and fungal infections. Although thrombocytopenia is a risk factor for invasive candidiasis, low platelet counts may persist despite adequate treatment and clinical improvement. ${ }^{50,51}$ Therefore, thrombocytopenia may not be an optimal indicator of onset or resolution of sepsis.

\section{CSF Cell Count and Chemistries}

Uninfected preterm or term infants have a CSF mean white blood cell count of less than 10 cells $/ \mathrm{mm}^{3}$, with an upper limit of 2 standard deviations equivalent to less than 20 cells $/ \mathrm{mm}^{3}{ }^{37,52,53} \mathrm{CSF}$ white blood cell band number does not predict culture-proven meningitis. ${ }^{54}$ Infants with meningitis attributable to gram-negative organisms have increased CSF parameters compared with infants with meningitis attributable to gram-positive organisms. ${ }^{55}$ The CSF protein concentration in the term uninfected infant is usually less than $100 \mathrm{mg} / \mathrm{dL}$; the CSF protein concentration of the uninfected preterm infant is higher than the term infant and is correlated with prematurity. ${ }^{56}$ The CSF glucose concentration in the term infant is usually between $70 \%$ and $80 \%$ of a simultaneously measured serum glucose; a low CSF glucose has the greatest specificity for bacterial meningitis. ${ }^{37,57}$ Bacterial meningitis may occur in infants with normal CSF parameters who concomitantly have a high concentration of bacterial organism. This observation accentuates the need to utilize culture-based and non-culture-based assessments in combination with clinical evaluation for optimal diagnosis and management.

\section{Acute Phase Reactants: C-Reactive Protein and Procalcitonin}

C-reactive protein (CRP) is associated with a humoral response to bacterial infection and increases within 6 to 8 hours of infection, with a peak noted 24 hours following infection. ${ }^{58,59}$ Low sensitivity within the first few hours of life may be due to delayed synthesis of interleukin-6 during the early immune response. Low CRP values should be considered in the context of infection timing. Two, within range, CRP assessments between 8 to 24 hours after birth and 24 hours later have a negative predictive value of $99.7 \%$ for cultureconfirmed neonatal sepsis. ${ }^{60}$ Host characteristics, including gestational age, may need to be considered with interpretation of CRP values. ${ }^{61}$ CRP assessment may provide guidance for discontinuation of antimicrobial therapy after 48 hours of empiric treatment, but measurement may not be beneficial to determine total duration of antimicrobial therapy.

Procalcitonin measurements appear to have better sensitivity but less specificity than CRP for identifying infants with neonatal sepsis. ${ }^{62}$ Values appear to increase 2 hours following 
pathogen exposure, peak within 12 hours, and return to baseline levels within 48 to 72 hours in healthy adults. ${ }^{63}$ An increase in procalcitonin levels can also occur after parturition and in conditions without a known infectious etiology, such as respiratory distress syndrome. ${ }^{64}$ As procalcitonin reference levels have become available for preterm and term infants and the assay has become available in clinical laboratories, this test is increasingly being used in assessing response to antimicrobial therapy and determining duration. ${ }^{65}$ Both CRP and procalcitonin measurements have been utilized in some centers to guide management of infants with suspected sepsis. The improved negative predictive value of serial CRP assessments compared with a single CRP measurement should be considered when comparing studies of acute phase reactants.

\section{Sepsis Screening Panels/Scores}

A variety of sepsis panels and scoring systems have been devised to increase the positive predictive value of individual parameters for neonatal sepsis. Overall, positive predictive value is increased when assessments are obtained after 24 hours of life. A cytokine scoring system combining measurements of granulocyte colony-stimulating factor (G-CSF), interleukin-6, interleukin-8, and tumor necrosis factor- $\alpha$ from 226 neonates $>3$ days old with clinical sepsis was noted to have $100 \%$ sensitivity and a $69 \%$ positive predictive value for gram-negative bacteremia. ${ }^{66}$ However, most scoring systems are more applicable for their negative predictive value and consequently for discontinuation of antimicrobial therapy. ${ }^{45,67,68}$

\section{Management}

Empiric treatment is often initiated in infants thought to be at risk for sepsis, either because of clinical signs and symptoms or pregnancy-related risk factors (-Table $\mathbf{2}$ ).

Ampicillin and an aminoglycoside are recommended as empiric therapy for EOS, unless there is an epidemiological or clinical indication for broader-spectrum therapy with a cephalosporin or carbapenem. If an organism is not isolated and there is no clinical evidence of infection, most clinicians discontinue antimicrobial therapy after 48 hours. $^{39}$ The empiric use of cephalosporins is discouraged due to an increased risk for the development of resistance and candidiasis; however, cephalosporins may be indicated if gram-negative meningitis is suspected. ${ }^{69-72}$ For empiric third-generation cephalosporin therapy in neonates, cefotaxime is preferred over ceftriaxone due to the potential displacement of bilirubin and potential for kernicterus observed with ceftriaxone.

\section{Duration of Treatment}

Bacteremia without a focus is treated for 7 to 10 days. When uncomplicated meningitis attributable to GBS is diagnosed, therapy is extended to 14 days. Complications including cerebritis, osteomyelitis, and endocarditis require extended courses of treatment. For gram-negative meningitis, some experts recommend the longer of 14 days after the first negative culture or a total course of 21 days with cefotaxime and an aminoglycoside until culture results are known. ${ }^{73}$
The optimal empiric therapy and duration for culturenegative clinical sepsis is unknown. Antibiotic treatment of mothers during labor for GBS prophylaxis, suspected chorioamnionitis, or PPROM may reduce the opportunity to isolate a pathogen from the newborn. In many clinical situations, it may be impractical to perform a lumbar puncture to assess for meningitis, and empiric treatment for duration to treat potential meningitis may be indicated. Several studies have associated antimicrobial treatment for greater than 5 days in newborns with culture-negative clinical sepsis with increased risk of death and NEC. ${ }^{74-77}$ This observation may be due to the presence of an unrecognized noninfectious etiology mimicking the presentation of clinical sepsis or to complications from extended courses of empiric antimicrobial therapy.

\section{Management of Candidiasis}

The polyenes including amphotericin B deoxycholate and lipid amphotericin preparations are traditional choices for invasive candidiasis. Amphotericin B deoxycholate is well tolerated by neonates who do not exhibit many of the toxicities seen in older children. Fluconazole, with the option of intravenous and oral administration, has activity against approximately $95 \%$ of common neonatal candida isolates. However, if invasive candidiasis occurs in a neonate who has received fluconazole prophylaxis, an antifungal from a different class is recommended for treatment. Fluconazole pharmacokinetics demonstrates that doses between 6 and 12 $\mathrm{mg} / \mathrm{kg}$ per day achieve serum concentrations adequate for treatment of neonatal candidiasis. ${ }^{25,78,79}$ The echinocandins, semisynthetic lipopeptides produced via chemical modification of natural products of fungi, have excellent efficacy against most species of Candida and have a comparatively benign safety profile. ${ }^{80,81}$ They have excellent soft tissue and bone penetration, with application in hepatosplenic candidiasis and osteomyelitis.

Although there have been case reports of hepatic insufficiency in some pediatric recipients of the echinocandins, as a class, these agents are well tolerated in the neonate. ${ }^{82-85}$ Two of the most commonly used echinocandins, caspofungin and micafungin, have comparative susceptibility and safety profiles. There are ongoing pharmacokinetic trials of anidulafungin in neonates. Disadvantages of echinocandin use include the higher minimal inhibitory concentration for Candida parapsilosis. Additionally, the central nervous system (CNS) penetration of the echinocandins is not optimal. If the possibility of CNS infection exists, the use of an agent with established CNS penetration, such as amphotericin or fluconazole, should be considered. In situations where CNS involvement is unknown or cannot be assessed, an echinocandin could be used in combination with amphotericin or fluconazole. There is no best empiric antifungal for suspected or recognized neonatal candidiasis; rather, the selection of agent(s) should be guided by the clinical presentation and history of antifungal agents received.

Assuming that an antifungal with activity against the organism(s) isolated is administered at the appropriate dose, bloodstream clearance should occur within 3 to 5 days following 
Table 2 Management and prevention of neonatal sepsis

\begin{tabular}{|c|c|c|}
\hline Condition & Therapy & Additional considerations \\
\hline \multicolumn{3}{|l|}{ Empiric management } \\
\hline Early onset sepsis & $\begin{array}{l}\text { Ampicillin + aminoglycoside: } 10 \mathrm{~d} \text { for } \\
\text { bacteremia; } 14 \mathrm{~d} \text { for GBS and } \\
\text { uncomplicated meningitis; extend } \\
\text { to } 21 \text { to } 28 \mathrm{~d} \text { for complicated } \\
\text { infections }\end{array}$ & $\begin{array}{l}\text { Consider a third-generation cephalosporin } \\
\text { (cefotaxime preferred) or carbapenem for } \\
\text { meningitis. Tailor therapy to pathogen. } \\
\text { Consider discontinuation of therapy if } \\
\text { pathogen not isolated. }\end{array}$ \\
\hline Late-onset sepsis & $\begin{array}{l}\text { Vancomycin }+ \text { aminoglycoside: duration } \\
\text { dependent on pathogen and site }\end{array}$ & $\begin{array}{l}\text { Alternatives to vancomycin may be } \\
\text { considered based on local epidemiology } \\
\text { and clinical presentation. Aminoglycoside-based } \\
\text { regimen preferred to cephalosporin given } \\
\text { reduced risk of resistance. Consider cephalosporin } \\
\text { if meningitis suspected. Consider a carbapenem } \\
\text { if third-generation cephalosporin recently received. } \\
\text { Consider amphotericin for fungal etiologies. } \\
\text { Tailor therapy to pathogen. Consider } \\
\text { discontinuation of therapy if pathogen } \\
\text { not isolated. }\end{array}$ \\
\hline \multicolumn{3}{|c|}{ Non-antimicrobial treatment strategies } \\
\hline $\begin{array}{l}\text { Recombinant G-CSF } \\
\text { Recombinant G-MSF }\end{array}$ & $\begin{array}{l}\text { Enhance neutrophil number and function, } \\
\text { but no reduction in infection when } \\
\text { administered as prophylaxis or } \\
\text { improvement in survival when } \\
\text { administered as therapy }\end{array}$ & $\begin{array}{l}\text { Insufficient evidence to support the clinical } \\
\text { use of G-CSF or GM-CSF either as treatment } \\
\text { or prophylaxis to prevent systemic } \\
\text { infections. } 104\end{array}$ \\
\hline IVIG & $\begin{array}{l}\text { Augments antibody-dependent cytotoxicity } \\
\text { and improves neutrophilic function, but } \\
\text { no evidence that IVIG in suspected or } \\
\text { proven sepsis reduces death }\end{array}$ & $\begin{array}{l}\text { Insufficient evidence from } 10 \text { RCTs or } \\
\text { quasi-RCTs to support use in neonates } \\
\text { with confirmed or suspected sepsis. }\end{array}$ \\
\hline \multicolumn{3}{|l|}{ Prevention strategies } \\
\hline IAP & $\begin{array}{l}\text { Administration of penicillin or ampicillin } \\
4 \mathrm{~h} \text { prior to parturition }\end{array}$ & $\begin{array}{l}\text { Successfully reduces rates of EOS due to } \\
\text { GBS. No effect on LOS GBS. }\end{array}$ \\
\hline Fluconazole prophylaxis & $\begin{array}{l}\text { Administration of weight-based dosing } \\
\text { to neonates }<1,500 \mathrm{~g}\end{array}$ & $\begin{array}{l}\text { Most beneficial in NICUs with high baseline } \\
\text { rates of invasive candidiasis. }\end{array}$ \\
\hline $\begin{array}{l}\text { BLF supplementation } \\
\text { with a probiotic, LGG }\end{array}$ & $\begin{array}{l}\text { BLF is a human milk glycoprotein with a } \\
\text { role in innate immune response; LGG } \\
\text { enhances the activity of lactoferrin }\end{array}$ & $\begin{array}{l}\text { BLF supplementation with and without LGG } \\
\text { reduced the incidence of first LOS in } 472 \text { VLBW } \\
\text { neonates in large randomized, double-blind } \\
\text { RCT. Additional confirmatory studies } \\
\text { warranted. }\end{array}$ \\
\hline
\end{tabular}

Abbreviations: BLF, bovine lactoferrin; EOS, early onset sepsis; GBS, group B streptococcus; G-CSF, granulocyte colony-stimulating factor; GM-CSF, granulocyte macrophage-stimulating factor; IAP, intrapartum antimicrobial prophylaxis; IVIG, intravenous immunoglobulin; LGG, Lactobacillus rhamnosus GG; LOS, late-onset sepsis; NICU, neonatal intensive care unit; RCTs, randomized, controlled trials; VLBW, very low birth weight.

initiation of therapy. Rescreening after 5 days of therapy to document clearance of organisms is recommended. Consideration of a second antifungal agent may be warranted if there is evidence of an abscess, persistent candiduria, or 10 days of persistent organism isolation. ${ }^{24,86}$ Improvement in rates of fungal clearance from 67 to $96 \%$ with the addition of a second antifungal agent has been noted. ${ }^{87}$

There is debate regarding the need to remove central venous catheters (CVCs) in patients with invasive candidiasis. Improved outcomes have been noted in neonates with CVC removal. ${ }^{24,86,88}$ Replacement of the CVC at a different site, when continued central access is required, has been proposed an alternative to discontinuation of the CVC. Because a majority of neonates are CVC-dependent for parenteral nutrition and antifungal therapy, the maintenance of venous access is obligatory. ${ }^{24} \mathrm{~A}$ recent evaluation of CVC retention in nonneutropenic adults suggested that CVC removal within 48 hours of organism isolation may not affect outcome. ${ }^{89} \mathrm{~A}$ Cochrane Review in 2011 assessing early removal versus expectant management of CVCs in neonates with bloodstream infection did not identify any randomized controlled trials using standard search methods of the Cochrane Neonatal Review Group. The authors concluded that observational data suggest that early removal is associated with a decreased incidence of complications and prolonged detection of pathogens. However, the reviewers recommended caution in the application of these findings due to inherent study design biases. ${ }^{90}$ The American Academy of Pediatrics Committee on Infectious Diseases recommends removal of any infected vascular catheter and consideration of replacement when 
infection is controlled. ${ }^{73}$ Additional studies in preterm neonates are needed before definitive recommendations regarding CVC retention can be made in this population.

\section{Prevention of Candidiasis}

\section{Fluconazole Prophylaxis}

Prophylactic administration of fluconazole during the first 6 weeks of life reduces fungal colonization and invasive fungal infection in infants with birth weights $<1,000$ g. ${ }^{91}$ In addition to the individual benefit afforded by prophylaxis for VLBW neonates, fluconazole prophylaxis may have a community benefit by decreasing the overall fungal burden of a NICU. ${ }^{25}$ A single center was able to decrease invasive candidiasis mortality with fluconazole prophylaxis administered to highrisk neonates. ${ }^{92}$ Results from over 14 trials at multiple institutions with 3,100 neonates suggest that fluconazole prophylaxis decreases colonization of the urine, gastrointestinal tract, and integument, without promoting the development of resistance and without adverse effects. ${ }^{25,91-97}$ Targeted therapy of 3 $\mathrm{mg} / \mathrm{kg}$ of intravenous fluconazole initiated before 48 hours of life to neonates $<1,000 \mathrm{~g}$ and continued for the duration of intravenous access is a regimen that has been adopted by some NICUs with high baseline rates of candidiasis. ${ }^{95}$ Of note, enterally administered fluconazole does not appear to provide protection against CVC-associated candidiasis. ${ }^{25}$ Both the Infectious Diseases Society of America and the American Academy of Pediatrics support the administration of prophylactic fluconazole to preterm infants. ${ }^{73,88}$ Based on an annual U.S. preterm birth cohort of approximately 30,000 VLBW, it has been estimated that fluconazole prophylaxis could prevent about 2,000 to 3,000 cases of invasive candidiasis, about 200 to 300 deaths, and the adverse neurodevelopmental outcomes of invasive candidiasis in approximately 400 to 500 infants per year. ${ }^{25}$ Differing baseline rates of fungal infections, practices related to CVC removal, severity of illness, and practices related to the use of broad-spectrum antimicrobials make universal recommendations regarding prophylaxis challenging.

\section{Other Preventive Strategies}

Additional strategies that have been proposed to reduce the risk of invasive candidiasis include maternal decolonization, through targeted therapy of women with symptomatic vaginal candidiasis, or empiric therapy for all antepartum women. ${ }^{98}$ Neonatal practices that may reduce the risks of invasive candidiasis include limited use of broad-spectrum antimicrobials in hosts with documented resistant pathogens, use of an aminoglycoside instead of a cephalosporin for empiric therapy when meningitis or antimicrobial resistance is not suspected, limitation of postnatal steroid use in VLBW infants, early enteral feeding, and the establishment of the neonatal gut microbiome with human milk feeding. ${ }^{24,99}$ Infection prevention practices in the NICU, including the utilization of trained teams with standardized practices for the insertion and care of CVCs, have been shown to reduce the incidence of catheter-related infections. ${ }^{100,101}$ Active surveillance of organisms associated with infection, antifungal resistance, and outcomes is important to optimize management.

\section{Other Management Strategies}

Recombinant G-CSF and recombinant granulocyte-macrophage-stimulating factor (GM-CSF) have both been shown to enhance the neutrophil function of leukocytes removed from premature infants and evaluated in the laboratory setting. ${ }^{102}$ A prospective, randomized case-control study conducted over a 13-month period between 2009 and 2010 demonstrated that G-CSF administered to 60 neonates with clinical sepsis resulted in decreased antibiotic utilization and lengths of stay compared with 30 infants who did not receive G-CSF. ${ }^{103}$ Treatment with colony-stimulating factor therapy (G-CSF and GM-CSF) of 97 neonates who had documented culture-positive sepsis (largely due to gram-negative infection and GBS) and neutropenia (absolute neutrophil count $<1,700 / \mathrm{mL}$ ) significantly reduced the risk of death (relative risk 0.34 ; $95 \%$ CI: 0.12 to 0.92 ). ${ }^{104}$

These studies suggest the potential for enhancing immune response by supplementing conventional therapies with G-CSF or GM-CSF. However, large-scale randomized, placebo-controlled trials will be necessary to support the clinical use of G-CSF and GM-CSF. ${ }^{104,105}$

An interest in the potential benefits of intravenous immunoglobulin in the management of neonatal sepsis stems from the potential of supplemental immunoglobulin $G$ to activate the immune response by augmenting antibody-dependent cytotoxicity and improving neutrophil function. A Cochrane review of 10 randomized or quasi-randomized controlled trials of intravenous immunoglobulin for treatment of suspected bacterial or fungal infection in newborn infants $<28$ days of age concluded that there is still insufficient evidence to support the administration of intravenous immunoglobulin to prevent mortality in infants with clinical or cultureproven sepsis. ${ }^{106}$ Mortality or major morbidity at 2 years of age was compared in 3,493 infants from 113 hospitals in nine countries who received directed or empiric antimicrobial therapy and polyvalent immunoglobulin $\mathrm{G}$ immune globulin or a placebo. There were no significant differences in death, major or minor disability at age 2 years, incidence of subsequent sepsis episodes, and adverse events. These results did not support a benefit of immune globulin therapy to neonates with confirmed or suspected sepsis. ${ }^{107}$

\section{Prevention}

In the United States, IAP for the prevention of invasive GBS disease has been highly successful. Current recommendations call for universal screening of pregnant women at 35 to 37 weeks' gestation to identify those who are colonized with GBS and for the provision of IAP with penicillin or ampicillin to colonized women for at least 4 hours prior to delivery. In the rare situation of penicillin allergy, clindamycin is an alternative agent, if local epidemiology or isolate testing demonstrates susceptibility. ${ }^{16}$ IAP does not prevent late-onset GBS. The source of pathogens associated with LOS is from the environment, most often from providers who interact with the infant in the postnatal environment. Infection control strategies targeted toward the health care worker, including hand hygiene, are effective in reducing the risk of LOS. ${ }^{108}$ 
Assessing the risk of colonization from the health care environment requires reliable and rapid methods for assessing whether an organism represents endemic flora or a new outbreak strain. A focus on MRSA in the NICU setting demonstrated that high-throughput sequencing technology can distinguish between outbreak and endemic isolates and may assist with infection control in a clinically relevant time frame. ${ }^{109}$ Although the presence of resistant organisms is a focus of prevention efforts in many NICU settings, the comparable morbidity and mortality of infections with antimicrobial susceptible strains such as MSSA should be noted. Prevention efforts and resources should be devoted equally to reducing the prevalence of both resistant and susceptible organisms. ${ }^{22}$

The benefits of fluconazole prophylaxis in neonates weighing $<1,500 \mathrm{~g}$ for the prevention of candidiasis have been demonstrated in multiple studies and are most beneficial in NICUs with high baseline rates of invasive candidasis. ${ }^{23}$

The ability of bovine lactoferrin (BLF) supplementation alone and in combination with the probiotic Lactobacillus rhamnosus GG (LGG) to prevent neonatal sepsis was evaluated in a prospective, multicenter, double-blind, randomized placebo-controlled trial in 11 tertiary care NICUs. Over a 9-month period during 2007 to 2008, 472 VLBW neonates received placebo, LGG, and BLF or BLF only daily from birth through 30 days of life or 45 days for neonates with birth weights of $<1,000 \mathrm{~g}$. Compared with placebo, BLF supplementation with and without LGG reduced the incidence of the first LOS episode in VLBW neonates. Further studies of lactoferrin, with and without probiotics, to reduce risk of neonatal sepsis are indicated. ${ }^{110,111}$

\section{Conclusion}

The epidemiology of neonatal sepsis is a changing landscape. Early and late-onset neonatal sepsis continues to be associated with significant morbidity and mortality, including long-term morbidity. Surveillance for rates of infection, pathogens associated with infection and their antimicrobial susceptibility, antimicrobial and adjunctive treatments used, and short- and longterm outcomes is important as optimal prevention and treatment strategies are explored in larger scale clinical trials.

\section{References}

1 Tissières $\mathrm{P}$, Ochoda $\mathrm{A}$, Dunn-Siegrist I, et al. Innate immune deficiency of extremely premature neonates can be reversed by interferon- $\gamma$. PLoS ONE 2012;7:e32863

2 Wynn JL, Levy O. Role of innate host defenses in susceptibility to early-onset neonatal sepsis. Clin Perinatol 2010;37:307-337

3 Schrag SJ, Stoll BJ. Early-onset neonatal sepsis in the era of widespread intrapartum chemoprophylaxis. Pediatr Infect Dis J 2006;25:939-940

4 Schuchat A, Zywicki SS, Dinsmoor MJ, et al. Risk factors and opportunities for prevention of early-onset neonatal sepsis: a multicenter case-control study. Pediatrics 2000;105(1 Pt 1):21-26

5 Tita AT, Andrews WW. Diagnosis and management of clinical chorioamnionitis. Clin Perinatol 2010;37:339-354

6 Alexander JM. Epidural analgesia for labor pain and its relationship to fever. Clin Perinatol 2005;32:777-787

7 Stoll BJ, Hansen NI, Bell EF, et al; Eunice Kennedy Shriver National Institute of Child Health and Human Development Neonatal
Research Network. Neonatal outcomes of extremely preterm infants from the NICHD Neonatal Research Network. Pediatrics 2010;126:443-456

8 Gibbs RS, Duff P. Progress in pathogenesis and management of clinical intraamniotic infection. Am J Obstet Gynecol 1991;164; (5 Pt 1):1317-1326

9 Romero R, Quintero R, Oyarzun E, et al. Intraamniotic infection and the onset of labor in preterm premature rupture of the membranes. Am J Obstet Gynecol 1988;159:661-666

10 Goldenberg RL, Andrews WW, Goepfert AR, et al. The Alabama Preterm Birth Study: umbilical cord blood Ureaplasma urealyticum and Mycoplasma hominis cultures in very preterm newborn infants. Am J Obstet Gynecol 2008;198:e1-e5

11 Weston EJ, Pondo T, Lewis MM, et al. The burden of invasive earlyonset neonatal sepsis in the United States, 2005-2008. Pediatr Infect Dis J 2011;30:937-941

12 Stoll BJ, Hansen NI, Sánchez PJ, et al; Eunice Kennedy Shriver National Institute of Child Health and Human Development Neonatal Research Network. Early onset neonatal sepsis: the burden of group B streptococcal and $E$. coli disease continues. Pediatrics 2011;127:817-826

13 Hornik CP, Fort P, Clark RH, et al. Early and late onset sepsis in very-low-birth-weight infants from a large group of neonatal intensive care units. Early Hum Dev 2012;88(Suppl 2): S69-S74

14 Lim DV, Morales WJ, Walsh AF, Kazanis D. Reduction of morbidity and mortality rates for neonatal group $B$ streptococcal disease through early diagnosis and chemoprophylaxis. J Clin Microbiol 1986;23:489-492

15 Boyer KM, Gotoff SP. Prevention of early-onset neonatal group B streptococcal disease with selective intrapartum chemoprophylaxis. N Engl J Med 1986;314:1665-1669

16 Centers for Disease Control and Prevention. Prevention of Perinatal Group B Streptococcal Disease: Revised Guidelines from CDC, 2010. MMWR 2010:1-36

17 Moore MR, Schrag SJ, Schuchat A. Effects of intrapartum antimicrobial prophylaxis for prevention of group-B-streptococcal disease on the incidence and ecology of early-onset neonatal sepsis. Lancet Infect Dis 2003;3:201-213

18 Stoll BJ, Hansen N, Fanaroff AA, et al. Late-onset sepsis in very low birth weight neonates: the experience of the NICHD Neonatal Research Network. Pediatrics 2002;110(2 Pt 1):285-291

19 Glasgow TS, Young PC, Wallin J, et al. Association of intrapartum antibiotic exposure and late-onset serious bacterial infections in infants. Pediatrics 2005;116:696-702

20 Cohen-Wolkowiez M, Moran C, Benjamin DK, et al. Early and late onset sepsis in late preterm infants. Pediatr Infect Dis J 2009;28: 1052-1056

21 Healy CM, Baker CJ, Palazzi DL, Campbell JR, Edwards MS. Distinguishing true coagulase-negative Staphylococcus infections from contaminants in the neonatal intensive care unit. J Perinatol 2012

22 Shane AL, Hansen NI, Stoll BJ, et al; Eunice Kennedy Shriver National Institute of Child Health and Human Development Neonatal Research Network. Methicillin-resistant and susceptible Staphylococcus aureus bacteremia and meningitis in preterm infants. Pediatrics 2012;129:e914-e922

23 Leibovitz E. Strategies for the prevention of neonatal candidiasis. Pediatr Neonatol 2012;53:83-89

24 Benjamin DK Jr, Stoll BJ, Fanaroff AA, et al; National Institute of Child Health and Human Development Neonatal Research Network. Neonatal candidiasis among extremely low birth weight infants: risk factors, mortality rates, and neurodevelopmental outcomes at 18 to 22 months. Pediatrics 2006;117:84-92

25 Kaufman DA. Challenging issues in neonatal candidiasis. Curr Med Res Opin 2010;26:1769-1778

26 Benjamin DK Jr, Poole C, Steinbach WJ, Rowen JL, Walsh TJ. Neonatal candidemia and end-organ damage: a critical appraisal 
of the literature using meta-analytic techniques. Pediatrics 2003;112(3 Pt 1):634-640

27 Benjamin DK Jr, Stoll BJ, Gantz MG, et al; Eunice Kennedy Shriver National Institute of Child Health and Human Development Neonatal Research Network. Neonatal candidiasis: epidemiology, risk factors, and clinical judgment. Pediatrics 2010;126:e865-e873

28 Ascher SB, Smith PB, Watt K, et al. Antifungal therapy and outcomes in infants with invasive Candida infections. Pediatr Infect Dis J 2012;31:439-443

29 Stoll BJ, Hansen NI, Adams-Chapman I, et al; National Institute of Child Health and Human Development Neonatal Research Network. Neurodevelopmental and growth impairment among extremely low-birth-weight infants with neonatal infection. JAMA 2004;292:2357-2365

30 Ascher SB, Smith PB, Clark RH, et al. Sepsis in young infants with congenital heart disease. Early Hum Dev 2012;88(Suppl 2): S92-S97

31 Schelonka RL, Chai MK, Yoder BA, Hensley D, Brockett RM, Ascher DP. Volume of blood required to detect common neonatal pathogens. J Pediatr 1996;129:275-278

32 Neal PR, Kleiman MB, Reynolds JK, Allen SD, Lemons JA, Yu PL. Volume of blood submitted for culture from neonates. J Clin Microbiol 1986;24:353-356

33 Connell TG, Rele M, Cowley D, Buttery JP, Curtis N. How reliable is a negative blood culture result? Volume of blood submitted for culture in routine practice in a children's hospital. Pediatrics 2007; 119:891-896

34 Isaacs D, Barfield CP, Grimwood K, McPhee AJ, Minutillo C, Tudehope DI; Australian Study Group for Neonatal Infections. Systemic bacterial and fungal infections in infants in Australian neonatal units. Med J Aust 1995;162:198-201

35 May M, Daley AJ, Donath S, Isaacs D; Australasian Study Group for Neonatal Infections. Early onset neonatal meningitis in Australia and New Zealand, 1992-2002. Arch Dis Child Fetal Neonatal Ed 2005;90:F324-F327

36 Stoll BJ, Hansen N, Fanaroff AA, et al. To tap or not to tap: high likelihood of meningitis without sepsis among very low birth weight infants. Pediatrics 2004;113:1181-1186

37 Garges HP, Moody MA, Cotten CM, et al. Neonatal meningitis: what is the correlation among cerebrospinal fluid cultures, blood cultures, and cerebrospinal fluid parameters? Pediatrics 2006;117: 1094-1100

38 Wynn JL, Tan S, Gantz MG, et al; NICHD Neonatal Research Network. Outcomes following candiduria in extremely low birth weight infants. Clin Infect Dis 2012;54:331-339

39 Polin RA; Committee on Fetus and Newborn. Management of neonates with suspected or proven early-onset bacterial sepsis. Pediatrics 2012;129:1006-1015

40 Azizia M, Lloyd J, Allen M, Klein N, Peebles D. Immune status in very preterm neonates. Pediatrics 2012;129:e967-e974

41 Newman TB, Puopolo KM, Wi S, Draper D, Escobar GJ. Interpreting complete blood counts soon after birth in newborns at risk for sepsis. Pediatrics 2010;126:903-909

42 Rozycki HJ, Stahl GE, Baumgart S. Impaired sensitivity of a single early leukocyte count in screening for neonatal sepsis. Pediatr Infect Dis J 1987;6:440-442

43 Hornik CP, Benjamin DK, Becker KC, et al. Use of the complete blood cell count in early-onset neonatal sepsis. Pediatr Infect Dis J 2012;31:799-802

44 Hornik CP, Benjamin DK, Becker KC, et al. Use of the complete blood cell count in late-onset neonatal sepsis. Pediatr Infect Dis ] 2012;31:803-807

45 Gerdes JS. Clinicopathologic approach to the diagnosis of neonatal sepsis. Clin Perinatol 1991;18:361-381

46 Lloyd BW, Oto A. Normal values for mature and immature neutrophils in very preterm babies. Arch Dis Child 1982;57: 233-235

47 Gerdes JS, Polin RA. Sepsis screen in neonates with evaluation of plasma fibronectin. Pediatr Infect Dis J 1987;6:443-446
48 Bhandari V, Wang C, Rinder C, Rinder H. Hematologic profile of sepsis in neonates: neutrophil CD64 as a diagnostic marker. Pediatrics 2008;121:129-134

49 Streimish I, Bizzarro M, Northrup V, et al. Neutrophil CD64 as a diagnostic marker in neonatal sepsis. Pediatr Infect Dis J 2012;31: 777-781

50 Guida JD, Kunig AM, Leef KH, McKenzie SE, Paul DA. Platelet count and sepsis in very low birth weight neonates: is there an organism-specific response? Pediatrics 2003;111(6 Pt 1):1411-1415

51 Manzoni P, Mostert M, Galletto P, et al. Is thrombocytopenia suggestive of organism-specific response in neonatal sepsis? Pediatr Int 2009;51:206-210

52 Byington CL, Kendrick J, Sheng X. Normative cerebrospinal fluid profiles in febrile infants. J Pediatr 2011;158:130-134

53 Kestenbaum LA, Ebberson J, Zorc JJ, Hodinka RL, Shah SS. Defining cerebrospinal fluid white blood cell count reference values in neonates and young infants. Pediatrics 2010;125:257-264

54 Kanegaye JT, Nigrovic LE, Malley R, et al; American Academy of Pediatrics, Pediatric Emergency Medicine Collaborative Research Committee. Diagnostic value of immature neutrophils (bands) in the cerebrospinal fluid of children with cerebrospinal fluid pleocytosis. Pediatrics 2009;123:e967-e971

55 Smith PB, Cotten CM, Garges HP, et al. A comparison of neonatal Gram-negative rod and Gram-positive cocci meningitis. J Perinatol 2006;26:111-114

56 Shah SS, Ebberson J, Kestenbaum LA, Hodinka RL, Zorc JJ. Agespecific reference values for cerebrospinal fluid protein concentration in neonates and young infants. J Hosp Med 2011;6:22-27

57 Smith PB, Garges HP, Cotton CM, Walsh TJ, Clark RH, Benjamin DK $\mathrm{Jr}$. Meningitis in preterm neonates: importance of cerebrospinal fluid parameters. Am J Perinatol 2008;25:421-426

58 Gabay C, Kushner I. Acute-phase proteins and other systemic responses to inflammation. N Engl J Med 1999;340:448-454

59 Philip AG. Response of C-reactive protein in neonatal group B streptococcal infection. Pediatr Infect Dis 1985;4:145-148

60 Benitz WE, Han MY, Madan A, Ramachandra P. Serial serum Creactive protein levels in the diagnosis of neonatal infection. Pediatrics 1998;102:E41

61 Hofer N, Zacharias E, Müller W, Resch B. An update on the use of Creactive protein in early-onset neonatal sepsis: current insights and new tasks. Neonatology 2012;102:25-36

62 Benitz WE. Adjunct laboratory tests in the diagnosis of earlyonset neonatal sepsis. Clin Perinatol 2010;37:421-438

63 Dandona P, Nix D, Wilson MF, et al. Procalcitonin increase after endotoxin injection in normal subjects. J Clin Endocrinol Metab 1994;79:1605-1608

64 Lapillonne A, Basson E, Monneret G, Bienvenu J, Salle BL. Lack of specificity of procalcitonin for sepsis diagnosis in premature infants. Lancet 1998;351:1211-1212

65 Chiesa C, Natale F, Pascone $\mathrm{R}$, et al. C reactive protein and procalcitonin: reference intervals for preterm and term newborns during the early neonatal period. Clin Chim Acta 2011; 412:1053-1059

66 Raynor LL, Saucerman JJ, Akinola MO, Lake DE, Moorman JR, Fairchild KD. Cytokine screening identifies NICU patients with Gram-negative bacteremia. Pediatr Res 2012;71:261-266

67 Chiesa C, Panero A, Osborn JF, Simonetti AF, Pacifico L. Diagnosis of neonatal sepsis: a clinical and laboratory challenge. Clin Chem 2004;50:279-287

68 Lim L, Rozycki HJ. Postnatal SNAP-II scores in neonatal intensive care unit patients: relationship to sepsis, necrotizing enterocolitis, and death. J Matern Fetal Neonatal Med 2008;21:415-419

69 Bryan CS, John JF Jr, Pai MS, Austin TL. Gentamicin vs cefotaxime for therapy of neonatal sepsis. Relationship to drug resistance. Am J Dis Child 1985;139:1086-1089

70 Manzoni P, Esposito S, Gallo E, Gastaldo L, Farina D, Principi N. Switch therapy in full-term neonates with presumed or proven bacterial infection. J Chemother 2009;21:68-73 
71 Manzoni P, Rizzollo S, Decembrino L, et al. Recent advances in prevention of sepsis in the premature neonates in NICU. Early Hum Dev 2011;87(Suppl 1):S31-S33

72 Bégué $\mathrm{P}$, Floret $\mathrm{D}$, Mallet E, et al. Pharmacokinetics and clinical evaluation of cefotaxime in children suffering with purulent meningitis. J Antimicrob Chemother 1984;14(Suppl B):161-165

73 Pickering L, ed. Red Book: 2012 Report of the Committee on Infectious Diseases. 29th ed. Elk Grove Village, IL: American Academy of Pediatrics; 2012

74 Alexander VN, Northrup V, Bizzarro MJ. Antibiotic exposure in the newborn intensive care unit and the risk of necrotizing enterocolitis. J Pediatr 2011;159:392-397

75 Clark RH, Gordon P, Walker WM, Laughon M, Smith PB, Spitzer AR. Characteristics of patients who die of necrotizing enterocolitis. J Perinatol 2012;32:199-204

76 Cotton CM. Early, prolonged use of postnatal antibiotics increased the risk of necrotising enterocolitis. Arch Dis Child Educ Pract Ed 2010;95:94

77 Kuppala VS, Meinzen-Derr J, Morrow AL, Schibler KR. Prolonged initial empirical antibiotic treatment is associated with adverse outcomes in premature infants. J Pediatr 2011;159:720-725

78 Wade KC, Wu D, Kaufman DA, et al; National Institute of Child Health and Development Pediatric Pharmacology Research Unit Network. Population pharmacokinetics of fluconazole in young infants. Antimicrob Agents Chemother 2008;52:4043-4049

79 Wade KC, Benjamin DK Jr, Kaufman DA, et al. Fluconazole dosing for the prevention or treatment of invasive candidiasis in young infants. Pediatr Infect Dis J 2009;28:717-723

80 Carver PL. Micafungin. Ann Pharmacother 2004;38:1707-1721

81 Murdoch D, Plosker GL. Anidulafungin. Drugs 2004;64:22492258; discussion 2259-2260

82 Smith PB, Walsh TJ, Hope W, et al. Pharmacokinetics of an elevated dosage of micafungin in premature neonates. Pediatr Infect Dis J 2009;28:412-415

83 Sáez-Llorens X, Macias M, Maiya P, et al. Pharmacokinetics and safety of caspofungin in neonates and infants less than 3 months of age. Antimicrob Agents Chemother 2009;53:869-875

84 Natarajan G, Lulic-Botica M, Aranda JV. Refractory neonatal candidemia and high-dose micafungin pharmacotherapy. J Perinatol 2009;29:738-743

85 Benjamin DK Jr, Smith PB, Arrieta A, et al. Safety and pharmacokinetics of repeat-dose micafungin in young infants. Clin Pharmacol Ther 2010;87:93-99

86 Chapman RL, Faix RG. Persistently positive cultures and outcome in invasive neonatal candidiasis. Pediatr Infect Dis J 2000;19:822-827

87 Linder N, Klinger G, Shalit I, et al. Treatment of candidaemia in premature infants: comparison of three amphotericin B preparations. J Antimicrob Chemother 2003;52:663-667

88 Pappas PG, Kauffman CA, Andes D, et al; Infectious Diseases Society of America. Clinical practice guidelines for the management of candidiasis: 2009 update by the Infectious Diseases Society of America. Clin Infect Dis 2009;48:503-535

89 Brass EP, Edwards JE. Should the guidelines for management of central venous catheters in patients with candidemia be changed now? Clin Infect Dis 2010;51:304-306

90 Vasudevan C, McGuire W. Early removal versus expectant management of central venous catheters in neonates with bloodstream infection. Cochrane Database Syst Rev 2011;(8):CD008436

91 Kaufman D, Boyle R, Hazen KC, Patrie JT, Robinson M, Donowitz LG. Fluconazole prophylaxis against fungal colonization and infection in preterm infants. N Engl J Med 2001;345:16601666

92 Healy CM, Campbell JR, Zaccaria E, Baker CJ. Fluconazole prophylaxis in extremely low birth weight neonates reduces invasive candidiasis mortality rates without emergence of fluconazoleresistant Candida species. Pediatrics 2008;121:703-710

93 Bertini G, Perugi S, Dani C, Filippi L, Pratesi S, Rubaltelli FF. Fluconazole prophylaxis prevents invasive fungal infection in high-risk, very low birth weight infants. J Pediatr 2005;147:162-165

94 Healy CM, Baker CJ, Zaccaria E, Campbell JR. Impact of fluconazole prophylaxis on incidence and outcome of invasive candidiasis in a neonatal intensive care unit. J Pediatr 2005;147:166-171

95 Kaufman D. Fluconazole prophylaxis decreases the combined outcome of invasive Candida infections or mortality in preterm infants. Pediatrics 2008;122:1158-1159; author reply 1159

96 Manzoni P, Stolfi I, Pugni L, et al; Italian Task Force for the Study and Prevention of Neonatal Fungal Infections; Italian Society of Neonatology. A multicenter, randomized trial of prophylactic fluconazole in preterm neonates. N Engl J Med 2007;356:2483-2495

97 Uko S, Soghier LM, Vega M, et al. Targeted short-term fluconazole prophylaxis among very low birth weight and extremely low birth weight infants. Pediatrics 2006;117:1243-1252

98 Kaufman D, Fairchild KD. Clinical microbiology of bacterial and fungal sepsis in very-low-birth-weight infants. Clin Microbiol Rev 2004; $17: 638-680$

99 Noyola DE, Fernandez M, Moylett EH, Baker CJ. Ophthalmologic, visceral, and cardiac involvement in neonates with candidemia. Clin Infect Dis 2001;32:1018-1023

100 Schulman J, Stricof R, Stevens TP, et al; New York State Regional Perinatal Care Centers. Statewide NICU central-line-associated bloodstream infection rates decline after bundles and checklists. Pediatrics 2011;127:436-444

101 Aly H, Herson V, Duncan A, et al. Is bloodstream infection preventable among premature infants? A tale of two cities. Pediatrics 2005; 115:1513-1518

102 Del Vecchio A, Christensen RD. Neonatal neutropenia: what diagnostic evaluation is needed and when is treatment recommended? Early Hum Dev 2012;88(Suppl 2):S19-S24

103 El-Ganzoury MM, El-Farrash RA, Saad AA, Mohamed AG, ElSherbini IG. In vivo effect of recombinant human granulocyte colony-stimulating factor on neutrophilic expression of CD11 b in septic neonates: a randomized controlled trial. Pediatr Hematol Oncol 2012;29:272-284

104 Carr R, Modi N, Doré CG-CSF. G-CSF and GM-CSF for treating or preventing neonatal infections. Cochrane Database Syst Rev 2003;(3):CD003066

105 Napolitano LM. Immune stimulation in sepsis: to be or not to be? Chest 2005;127:1882-1885

106 Ohlsson A, Lacy J. Intravenous immunoglobulin for suspected or subsequently proven infection in neonates. Cochrane Database Syst Rev 2010;(3):CD001239

107 Brocklehurst P, Farrell B, King A, et al; INIS Collaborative Group. Treatment of neonatal sepsis with intravenous immune globulin. N Engl J Med 2011;365:1201-1211

108 Morinis J, Shah J, Murthy P, Fulford M. Horizontal transmission of group B streptococcus in a neonatal intensive care unit. Paediatr Child Health (Oxford) 2011;16:e48-e50

109 Köser CU, Holden MT, Ellington MJ, et al. Rapid whole-genome sequencing for investigation of a neonatal MRSA outbreak. N Engl J Med 2012;366:2267-2275

110 Manzoni P, Rinaldi M, Cattani S, et al; Italian Task Force for the Study and Prevention of Neonatal Fungal Infections, Italian Society of Neonatology. Bovine lactoferrin supplementation for prevention of late-onset sepsis in very low-birth-weight neonates: a randomized trial. JAMA 2009;302:1421-1428

111 Pammi M, Abrams SA. Oral lactoferrin for the treatment of sepsis and necrotizing enterocolitis in neonates. Cochrane Database Syst Rev 2011;(10):CD007138 